\title{
Can we reduce maternal suicides?
}

\author{
M R M Rishard, A K P Ranaweera, H M Senanayake ${ }^{1}$
}

Sri Lanka Journal of Obstetrics and Gynaecology 2012; 34: 123-124

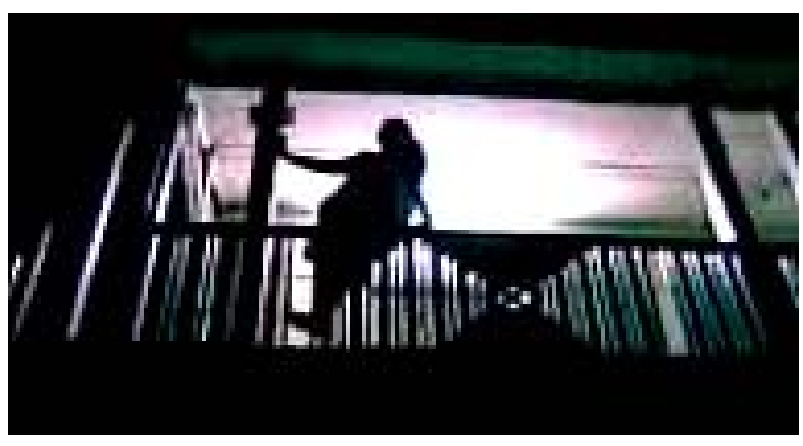

Figure 1. This picture was taken when the lady with puerperal psychosis was attempting to jump to her death.

It was an episode we will never forget. A woman who had had a vaginal delivery was threatening to jump to her death from the first floor of our hospital. No amount of persuasion seemed to assuage her and in fact only made her more aggressive. We managed to end the drama by pulling her out of the floor while a colleague was distracting her. She was diagnosed to have puerperal psychosis and managed appropriately. We were able to save her from a major injury or even death.

In Sri Lanka, reported maternal death due to suicide is notably high. Among 206 reported probable maternal deaths in 2010, 31 were due to suicide (Personal communication: Dr. Kapila Jayaratne, National Program Manager, Maternal Mortality Surveillance). Statistics from the UK show that in the first year after childbirth, suicide risk increases 70fold and suicide is the leading cause of maternal death up to 1 year after delivery in women in the triennium from 2001 to $2003^{1}$. This data highlight the gravity of this problem and may be applicable in Sri Lanka too. Failure to recognize the risk factors and institute appropriate treatment plans has emerged as a main contributory factor in the UK and many other countries. The trend may be universal.

\footnotetext{
${ }^{1}$ Professorial Unit, De Zoyza Maternity Hospital, Colombo. Correspondence: $M R$ R Rishard

E-mail:rishi7875@yahoo.com
}

Post partum psychosis and postpartum depression are two well known contributors to maternal morbidity and mortality ${ }^{2}$. The distinctive features of these mental disorders and underlying contributory factors need to be recognized by care givers to avert major catastrophes. 'Postpartum psychosis (PP) is the most severe form of post partum mental disorders, affecting 1-2 per 1000 women typically in first two weeks after delivery ${ }^{3,4}$. Puerperal hormonal shifts ${ }^{5}$, obstetrical complications ${ }^{6}$, sleep deprivation $^{7}$ and increased environmental stress are recognized contributing factors to the onset of illness. Etiology of PP is not known.

Previous psychiatric illness remains an important risk factor for post-partum psychosis ${ }^{8}$. It has been shown that one in seven women with previous history of PP has a risk of recurrence ${ }^{9}$ and women with bipolar disorder or schizoaffective disorder have a $50 \%$ risk having an episode of $\mathrm{PP}^{10}$. Data also show that Preexisting bipolar disorder (also known as manicdepressive disorder), other serious affective disorder and personal history of puerperal psychosis predicts a $50 \%$ risk of early postpartum major mental illness ${ }^{11}$.

PP presents as a rapidly evolving manic or mixed episode with restlessness, insomnia, irritability, rapidly shifting depressed or elated mood and disorganized behavior ${ }^{12}$. The consequences include suicide and infanticide ${ }^{13}$. It has also been noted that majority of these women die violently by jumping from a height or hanging ${ }^{14}$. This is particularly unfortunate since the response to treatment is $\operatorname{good}^{15}$. It is a psychiatric emergency and treatment can be life saving. Unfortunately, delay in institution of treatment is common since care providers are ill equipped to recognize the warning signs of PP. This was the case in our patient as well.

Post partum depression occurs in about $13 \%$ of women after delivery ${ }^{16}$. Etiology of postpartum depression remains unclear and there is little evidence to support a biological basis. Features of this illness are much the same as for non-postnatal depressive illness. Women with the history of intimate partner violence, sexual abuse or assault, use of illegal drugs, self-harm and lack of social support are at higher risk of depressive illness and suicide during pregnancy ${ }^{17}$. Although post partum depression tends to manifest at 4-6 weeks post partum, severe postnatal depressive 
illness has an early onset in the first few weeks following birth ${ }^{2}$. Those who have severe symptoms are probably at increased risk of suicide and, rarely, infanticide ${ }^{18}$. Thus, this condition needs to be speedily identified and treated by the caregivers.

It is probable that in Sri Lanka, not enough is being done to detect the risk of suicide in pregnancy. Higher number of suicidal deaths also highlights the need of better mental health services in the country as suicide is one of the determinants measuring the effectiveness of mental healthcare. The use validated Edinburgh post partum depression scale (EPDS) has been included in to our national program which has been recently launched. This questionnaire is meant to screen the presence postpartum depression at one month post partum and the 10th question is about suicidal ideation.

But use of validated EPDS alone may not be adequate. Timely detection and adequate management of these disorders require co-ordination of a wide variety of primary and secondary care services ${ }^{19}$. Royal College of Obstetricians and Gynecologists recommends that all maternity staff should have basic training in the identification of current and past history of mental health problems in pregnancy and the postpartum period and when to refer to mental health and primary care services ${ }^{11}$. In addition to these measures, comprehensive in-depth reviews of each of maternal deaths due to suicide are also needed to improve our understanding of the circumstances surrounding them so that prevention and intervention strategies can be developed.

\section{References}

1. CEMD. Confidential inquiries into maternal deaths. Why mothers die, 1997-99. London: Royal College of Obstetricians and Gynaecologists, 2001.

2. Oates M. Postnatal affective disorders. Part 1: an introduction. The Obstetrician \& Gynaecologist 2008; 10: 145-50.

3. Dean C, Kendell RE. The symptomatology of puerperal illnesses. Br J Psychiatry 1981; 139: 128.

4. Kendell RE, Chalmers JC, Platz C. Epidemiology of puerperal psychoses. Br J Psychiatry 1987; 150: 662-73.

5. Sichel DA, Driscoll JW. Women's moods. New York: William Morrow and Company, Inc., 1999.
6. Brockington IF, Oates M, Rose G. Prepartum psychosis. J Affective Disord 1990; 19: 31.

7. Sharma V, Smith A, Khan M. The relationship between duration of labour, time of delivery, and puerperal psychosis. J Affective Disord 2004; 83: 215.

8. Harlow BL, Vitonis AF, Sparen P, Cnattingius S, Joffe H. Incidence of hospitalization for postpartum psychotic and bipolar episodes in women with and without prior pre pregnancy or prenatal psychiatric hospitalizations. Arch Gen Psychiatry 64: 42-8.

9. Kendell R, Chalmers J, Platz C. Epidemiology of puerperal psychoses. Br J Psychiatry 1987; 150: 662.

10. Brockington IF. Puerperal psychosis: Motherhood and mental health. New York: Oxford University Press,1996: 200.

11. Royal College of Obstetricians and Gynaecologists. Management of Women with Mental Health Issues during Pregnancy and the Postnatal Period. Good practice No 14. London: RCOG; 2011.

12. Sharma V. Treatment of postpartum psychosis: challenges and opportunities. Curr Drug Saf 2008; 3(1): 76-81.

13. Appleby L, Mortensen PB, Faragher EB. Suicide and other causes of mortality after post-partum psychiatric admission. Br J Psychiatry 1998; 173: 209-11.

14. Oates M. Postnatal affective disorders. Part 2: prevention and management. The Obstetrician \& Gynaecologist 2008; 10: $231-5$.

15. Appleby L, Warner R, Whitton A, Faragher B. A controlled study of fluoxetine and cognitive-behavioural counselling in the treatment of postnatal depression. BMJ 1997; 314: 932-6.

16. O'Hara MW, Swain AM. Rates and risks of postpartum depression - a meta-analysis. Int Rev Psychiatry 1996; 8: 37.

17. National Collaborating Centre for Women's and Children's Health, National Institute for Health and Clinical Excellence. Pregnancy and complex social factors: A model for service provision for pregnant women with complex social factors. London: RCOG; 2010.[http://guidance.nice.org.uk/ CG110].

18. Confidential Enquiry into Maternal and Child Health. Why Mothers Die 2000-2002. The Sixth Report of the Confidential Enquiries into Maternal Deaths in the United Kingdom. London: RCOG Press; 2004.

19. SIGN. Postnatal Depression and Puerperal Psychosis: A National Clinical Guideline. Scottish Intercollegiate Guidelines Network. 2002. 